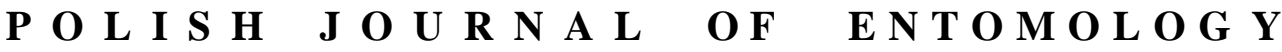

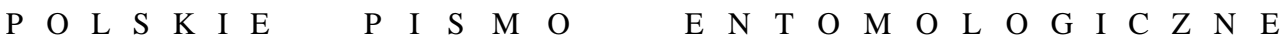

VOL. 84: 275-287

Lublin

30 December 2015

DOI: $10.1515 /$ pjen-2015-0024

\section{A theory about the evolutionary history of Lachnidae and comments on the results of some molecular phylogenetic studies of aphids (Hemiptera: Aphidoidea)*}

\author{
OLE E. HeIE \\ Holtegaardsvej 57, DK-2840 Holte, Denmark, e-mail: o.e.heie@mail.dk
}

\begin{abstract}
Several characters of the Lachnidae are discussed, and it is explained why some of them are not plesiomorphies as previously believed, but apomorphies. This applies e.g. to the absence of host alternation in the extant genera, to the short cauda and to the presence of compound eyes in the nymphs and the apterous adults. Some characters are adaptations to attention by ants or ways of feeding. It is concluded that many characters show that the family is relatively young and probably originally had host alternation of the same kind as Aphididae, which is regarded as the sister group. The results of some molecular phylogenetic studies are discussed.
\end{abstract}

KEY WORDS: Aphidoidea, Lachnidae, evolution, fossil aphids, phylogeny, host alternation, DNA.

\section{LACHNID CHARACTERS}

The lachnids are rather large and often brownish and densely haired aphids, most of them producing wax from small pores, with normal compound eyes with triommatidia in both nymphs and aperous adults, except in some species of Tramini. The head of most genera have a distinct longitudinal, mid-dorsal suture. Paired marginal and dorsal tubercles are absent. The primary rhinaria (olfactorial organs on the antennal segments V and VI) are not surrounded by minute hairs. The secondary rhinaria are circular, subcircular or oval, occasionally present on all four segments of the antennal flagellum, frequently placed close

\footnotetext{
* The paper is dedicated to Prof. Wacław WOJCIECHOWSKI in recognition of his great contribution to the taxonomy and faunistics of Hemiptera.
} 
to the apices of the segments. The processus terminalis is shorter than the basal part of the ultimate antennal segment. The rostrum of most genera is long, in some cases extremely long, and its distal segment is usually distinctly divided into two parts, segments IV and V. Numerous hairs are present on the first tarsal segment. The empodial hairs are simple and very short, inconspicous, almost residual. The siphunculi are pore-shaped and placed on low cones or sclerites, except in the tribe Tramini, where they are very small or absent. Three rudimentary gonapophyses are present, the middle one being very small. The cauda is short, broadly rounded and wearing numerous hairs. The anal plate is rounded. The majority of species feed on trunks or branches of trees. Only species of the tribe Tramini live on roots of herbs. Most species are attended by ants. In the autumn the sexuales are born, the female being apterous and oviparous, the male apterous or alate, but anholocycle also occurs, e.g. in Trama HEYDEN, 1837, Tuberolachnus MORDVILKO, 1909 and Stomaphis WALKER, 1870.

A Lachnus BURMEISTER, 1835 genus-group was first mentioned by KOCH (1854). The taxon Lachnidae HERRICH-SCHAEFFER in KOCH, 1857, was treated as a tribe (hence Lachnini) by BAKER (1920) within the subfamily Aphidinae, but BÖRNER (1952) changed the category into family status, which has been followed by HEIE (1980) and others. More recently REMAUDIÉRE \& REMAUDIÉRE (1997) treated lachnids as a subfamily Lachninae within Aphididae, the latter corresponding to Aphidoidea sensu HEIE (1980). The taxon Aphidoidea sensu HEIE (1980) contains all families with siphunculi or siphuncular pores. It is a superfamily within the infraorder Aphidomorpha BECKER-MIGDISOVA \& AIZENBERG, 1962 (HEIE \& WEGIEREK 2009), which originated in the Triasssic or in the Upper Permian. Aphids with siphuncular pores (Aphidoidea) have existed since the Middle Jurassic (HUANG et al. 2012) or earlier, but until the end of the Cretaceous most aphids belonging to extinct families did not have such structures.

\section{THE CLASSIFICATION OF LACHNIDAE}

Originally the lachnids were divided into three subfamilies, Lachninae, Eulachninae and Traminae, but recently it was discovered that the Lachninae was a paraphyletic subfamily, because phylogenetic studies found that the Trama-group nested within Lachninae taxa. It was shown by ZHANG \& CHEN (1999), who on the basis of cladistic analyses of morphological characters found that the Trama-group was a sister group of Lachnus + Tuberolachnus + Maculolachnus GAUMONT, 1920 + Pterochloroides MORDVILKO, 1914, while LAMPEL \& BURGENER $(1985,1987)$ and CZYLOK $(1990)$ concluded that the Tramagroup was closely related to the genus Stomaphis within the Lachninae. In a molecular phylogenetic study NORMARK (2000) also found support for a sister-group relationship 
between Tuberolachnini and Tramini, and that that they together are the sister group of Stomaphidini. Therefore it is obvious that Lachninae would be paraphyletic if Trama and relatives were maintained as a separate subfamily (HEIE 1995). The current taxonomic divisions of the family Lachnidae are consequently as follows (numbers in brackets indicate the numbers of species):

\section{Lachninae HERRICH-SCHAEFFER in KOCH, 1854}

Rostrum long, with apical segment (segments IV + V) normally short and blunt. Radial sector curved, rather long, leaving the middle or the apical part of the pterostigma. Media mostly distinctly visible, with two or three branches, in Tramini sometimes unbranched.

\section{Lachnini HERRICH-SCHAEFFER in KOCH, 1854}

Rostrum shorter than body. Compound eyes present in all morphs. Holocyclic. Males with rostrum. Feeding on deciduous trees. - Genera: Lachnus (22), Longistigma WILSON, 1909 ( $2+1$ fossil), Maculolachnus (4), Neonippolachnus SHINJI, 1924 (1), Pterochloroides (1), Pyrolachnus Basu \& Hille Ris Lambers, 1968 (3), Sinolachnus Hille Ris Lambers, 1956 (2), Lachnarius HEIE, 2006 (1 fossil).

\section{Stomaphidini MORDVILKO, 1914}

Rostrum much longer than body. Compound eyes present in all morphs. Holocyclic. Males without rostrum. Feeding on deciduous trees. - Genus: Stomaphis ( $24+1$ fossil).

\section{Tuberolachnini MAMONTOVA, 1972}

Rostrum shorter than body. Compound eyes present in all morphs. Mostly anholocyclic. Feeding on deciduous trees. - Genus: Tuberolachnus (2), Nippolachnus MATSUMURA, 1917 (2)

\section{Tramini HERRICH-SCHAEFFER in KOCH, 1854}

Rostrum shorter than body. Eyes of nymphs and apterae very small or absent. Media less distinctly visible than cubitus. Hind tarsi extremely long. Mostly anholocyclic (Blackman et al. 2001). Feeding on roots of herbaceous plants, mostly composites. Genera: Eotrama HILle RIS LAMBERS, 1969 (4), Neotrama BAKER, 1920 (12), Protrama BAKER, 1920 (5), Trama (7).

\section{Eulachninae BAKER, 1920}

Apical segment of rostrum (segments IV and V) short and blunt or slender and pointed. Compound eyes present in all morphs. Radial sector short, straight, leaving the apical end of pterostigma. Media normally less distinctly visible than cubitus. Body often covered by 
wax. Holocyclic. Living on coniferous trees.

Eulachnini BAKER, 1920

Apical segment of rostrum (segments IV $+\mathrm{V}$ ) short, not quite distinctly subdivided into two parts. Body elongate, slender, at least twice as long as broad, occasionally slightly covered by wax. Primary rhinaria without a ring of small sclerites. Eyes without triommatidia. - Genera: Essigella Del GuerCiO, 1909 (13), Eulachnus Del GuERCiO, 1909 (17), Pseudessigella HILLE RIS LAMBERS, 1966 (1).

\section{Schizolachnini BÖRNER, 1952}

Apical segment of rostrum (segments IV $+\mathrm{V}$ ) short, not quite distinctly subdivided into two parts. Body oviform, about 1.6 times as long as broad. Primary rhinaria with a ring of small slerites. Eyes with triommatidia. - Genus: Schizolachnus MORDVILKO, 1909 (7).

\section{Cinarini BÖRNER, 1930}

Apical segment of rostrum (segments IV $+\mathrm{V}$ ) long, slender, very distinctly subdivided into two parts. Body oviform. Primary rhinaria with or without a ring of small sclerites. Eyes with triommatidia. - Genera: Cinara CURTIS, 1835 (223 + 4 fossils), Precinara ZHANG et al., 1994 (1 fossil).

\section{THE AGE OF LACHNIDAE}

Lachnidae was regarded as a very primitive group by BAKER (1920) and BÖRNER (1952). ORTIZ-RIVAS \& MARTINEZ-TORRES (2010) reconstructed Lachnidae as the sister group to all remaining aphids. In contrast HEIE (1980) and WOJCIECHOWSKI (1992) considered Lachnidae as being one of the youngest families within Aphidoidea. Many apparently plesiomorphic characters are adaptative, and also some other characters originally regarded as plesiomorphies are in fact apomorphies. Fossil lachnids are few and all from the Middle or the Upper Miocene, and most of them are species of recent genera. These fossils belong to the recent genera Stomaphis, Cinara, Longistigma and the extinct genera Lachnarius and Precinara (HEIE \& WEGIEREK 2011) and they have all been found in Miocene deposits or perhaps in deposits from the Lower Pliocene in the case of Longistigma caryae (HARRIS, 1841). The latter is a still living species in North America, which also has been as a fossil in Iceland (HEIE \& FRIEDRICH 1971) where its host plants have disappeared long ago. As the aphid fauna of Iceland is European (HEIE 1964), this may mean that this aphid species lived on both sides of the Atlantic Ocean long ago (the genus is also represented in Asia). It is interesting that it is a lachnid able to feed on more 
host plants than any other lachnid, i.e. trees belonging to 24 genera and 16 families (BLACKMAN \& EASTOP 1994). Its long, slender Mindarus-like pterostigma might be understood as a plesiomorphic character, but the radial sector emerges from the apical part of pterostigma and not its base as in Mindarus KoCH, 1857. This may mean that shape of the pterostigma in Longistigma is secondarily evolved.

On the basis of morphology the family Lachnidae has been considered as the sister group of Aphididae (HEIE 1980, WOJCIECHOWSKI 1992). Apomorphies common to Aphididae and Lachnidae include the presence of wax glands, the oval or circular secondary rhinaria and also the fact that the various morphs of most representatives are rather similar to each other. Previously it has been proposed (HILLE RIS LAMBERS 1964, HeIE 1967, HeIE \& WeGIEReK 2009) that nymphs of the Triassic or Permian ancestors of all aphids had triommatidia only instead of multifaceted eyes, because this is the case in most families within Aphidoidea and also in Adelgoidea and Phylloxeroidea, and that the development of apterous adult females, often also with only few ommatidia, happened much later as a result of neotenic evolution. Therefore, the presence of very small eyes or their absence in nymphs and apterous adults in Trama might be understood as a plesiomorphy, but I think that the explanation is quite different. This character must have something to do with adaptation to life in darkness on roots and consequently be an apomorphic character, and that nymphs (and also apterous adults) of the ancestor of Tramini therefore had compound eyes and not only triommatidia as in most other aphid families, which means that the neotenic evolution leading to formation of the apterous morphs with triommatia as the only eyes as in nymphs, which is known from Eriosomatidae, Anoeciidae and many other families, did not happen in Lachnidae and Aphididae. Evolution has gone in the opposite way in these two families and also in some drepanosiphids. The nymphs have become more similar to the adults! The fact, that the nymphs of some species of lachnids have secondary rhinaria also confirms this. Therefore the Lachnidae must be as old as the Aphididae, and their common ancestor must have been separated from Greenideidae earlier, before the split into Aphididae and Lachnidae. This could well mean, that the Lachnidae originated in the Cretaceous, if the Cretaceous fossil species Aphidocallis caudatus KonONOva, 1977 (KonONOVA 1977, HeIE \& WEGIEREK 1998) really belongs to the Aphididae. There may be some doubt about this because it is impossible to see if Aphidocallis caudatus had siphunculi or siphuncular pores. Probably Lachnidae originated later, as Aphidocallis might well belong to the group containing the ancestor of both Aphididae and Lachnidae or to an extinct family.

Until the last part of the Tertiary both Aphididae and Lachnidae were poor in species compared with their species number today, unlike the Drepanosiphidae and Eriosomatidae. This seems to indicate that both families are rather young. While a few aphidids have been found in Baltic amber from the Lower Tertiary, lachnids have however never been found 
among the many specimens of aphids described so far from Baltic amber, which is a product of conifer. Fossil lachnids have as mentioned above not been found until the middle of the Tertiary.

\section{ZOOGEOGRAPHY OF LACHNIDAE}

The family must have evolved in temperate regions in the northern hemisphere. While Lachnini and Eulachninae are found on both sides of the Atlantic ocean, Tramini seems to be exclusively palaearctic. This fact supports the theory that this tribe must have evolved after the split between America and Europe.

All Lachnidae and most Aphididae occur in the northern hemisphere, while many primitive aphids, e.g. members of Drepanosiphidae, e.g. Neophyllaphidinae, Lizeriinae and Pterastheniinae, are distributed in the tropics and in the southern hemisphere. This supports the theory that Lachnidae and Aphididae are relatively young, only about 40-50 million years old or even younger. At that time the tropical zone became a barrier (HEIE 1994).

\section{THE PHYLOGENETIC POSITION OF LACHNIDAE}

Previously (HEIE \& WEGIEREK 2009) I wrote "The final word with regard to solving the phylogenetic riddles has not been spoken yet. We have to wait for DNA-analyses ...". Many papers dealing with DNA-analyses have since been published. Among them two studies deal with the phylogeny of all Aphidoidea. ORTIZ-RIVAS \& MARTINEZ-TORRES (2010) used molecular data of a large number of species, and NovÀKOVÀ et al. (2013) used DNA of the symbiont Buchnera MUNSON et al., 1991. Both papers place Lachnidae in a systematic position different from that proposed by HEIE \& WEGIEREK (2009) and in this paper. The former found that Lachnidae represents an early branch of the phylogenetic tree, distantly related to Aphididae, and a lineage including Aphididae and Drepanosiphidae, while the latter found that Lachnidae seems to be a sister group of part of Drepanosiphidae and represents a branch far from Aphididae. As the latter also found that Drepanosiphidae consisted of two parts, 1) Drepanosiphinae and Chaitophorinae together with Neophyllaphidinae and Mindarinae and 2) Callaphidinae and Phyllaphidinae, I prefer the results found by ORTIZ-RIVAS \& MARTINEZ-TORRES (2010) or at least some of them, though also MACKAUER (1965) doubted that 1) Drepanosiphinae and 2) Callaphidinae + Phyllaphidinae were closely interrelated. ORTIZ-RIVAS \& MARTINEZ-TORRES (2010) found for instance that all the families (by them called subfamilies) proposed by e.g. HEIE \& WEGIEREK (2009) are monophyletic, including the drepanosiphids, which by many 
authors are placed in several groups, and also the close relationship between Drepanosiphinae and Chaitophorinae. I doubt for several reasons given here their view of Lachnidae as an old, primitive group. In their fig. 3 the distance between the roots of Aphididae and Lachnidae also is rather short. They found that all aphids feeding on gymnosperms and all their ancestors had done so since the Mesozoic, which had been found earlier by NORMARK (2000).

It seems to be a mystery why two studies of DNA have given two very different results. Perhaps Buchnera often mutates or can be transferred between aphid clones, as some interrelated groups have been widely separated in the phylogenetic tree by NovÀKOVÀ et al. (2013). Mutations in the aphids and in their symbionts may have been followed by mutations in the opposite directionn several times during the evolutionary history. Among the differences between the two molecular studies is the position of Thelaxidae. In ORTIZRIVAS \& MARTINEZ-TORRES (2010) it is close to Anoeciidae as in WOJCIECHOWSKI (1992), and in NovÀKOVÀ et al. (2013) it is close to Drepanosiphinae as in HEIE (1987).

It is a crucial question whether the presence in lachnids of siphuncular pores placed on low cones or sclerites instead of pronounced siphunculi is either a plesiomorphic character or an apomorphic character. The siphunculi of the ancestors of all families within Aphidoidea were only pores as in the extinct families Oviparosiphidae and Canadaphididae and as is retained in the extant Eriosomatidae, Hormaphididae, Anoeciidae and Phloeomyzidae as well as in some members of the families Drepanosiphidae and Greenideideidae. Pronounced siphunculi developed only in some other members of Drepanosiphidae and of Greenideidae, in most Aphididae and in the Cretaceous family Paraverrucosidae (POINAR \& BROWN 2005). Siphunculi and siphuncular pores function as defence weapons against enemies threatening clones where all members are genetically uniform as a result of diploid parthenogenesis, and they only become smaller or become lost when other means of defence are present, e.g. life in closed galls, underground life or protection by ants. If the siphunculi were pores in the ancestor of Lachnidae, then tubular siphunculi developed in Aphididae after the split between Lachnidae and Aphididae, in which case the first aphidids had only pores. If the Lachnidae ancestor really had tubular siphunculi, then the presence of only pores is a secondarily evolved apomorphic character. Nearly all lachnids are attended by ants, so the presence of pores instead of real siphunculi might perhaps be regarded as an adaptation to visitations by ants, and if so this evolution went even further in Trama troglodytes VON HEYDEN, 1837 which lives underground and has lost the pores completely, as also has Stomaphis asiphon SZELEGIEWICZ, 1975.

I prefer however the first mentioned possibility, which arguably is supported by the fact that there are no traces of pronounced siphunculi among the 331 recent species nor in the fossil species. The first lachnids must certainly have had pores instead of tubular siphunculi, and the same must then have been the case with regard to the unknown common 
ancestor to Aphididae and Lachnidae. The Miocene fossil representatives of Lachnidae had only pores, but we of course do not know lachnids from the Cretaceous or the Lower Tertiary at present. Perhaps they did not exist that early.

The shape of the cauda is typical of aphids visited by ants. It is short and rounded, so that an ant easily can reach the anus from which the aphid excretes the honeydew. This is an apomorphic character. Originally the Aphidoidea cauda was knobbed as in the extinct genus Oviparosiphum SHAPOSHNIKOV, 1979 and in many drepanosiphids.

Apart from the presence of siphuncular pores another apparently plesiomorphic character is the absence of host alternation, but this is probably really an apomorphic character in the Lachnidae, because at least some of its members obviously originally went through a life cycle with host alternation. No lachnid species is host-alternating today. Most species are associated with trees only, most members of Lachninae with deciduous trees and all members of Eulachninae with conifers. The only exception is the tribe Tramini, the species of which live on roots of herbaceous plants. This fact can be explained in two ways, of which I prefer the second one:

1. The ancestor of Tramini lived on trees, but conquered herbs as its only hosts, and it happened in one step (CZYLOK 1990).

2. The ancestor of Lachnidae was dioecious, host-alternating between a tree and a herbaceous plant, probably a composite. The Tramini lost their primary host, while all other lachnids lost their secondary hosts. It is a phenomenon known from several families. Species of Aphis LINNAEUS, 1758, Rhopalosiphum KocH, 1854, Dysaphis BÖRNER, 1931 and Macrosiphum PASSERINI, 1860 within Aphididae and many others have lost either their primary host or their secondary host.

The second possibility seems most obvious to me.

The family Anoeciidae contains several species, which are host-alternating between Cornus LinNAEUS, 1753 and roots of grasses, and also contains the species Anoecia zirnitzi MORDVILKO, 1931 and Paranoecia pskovica MORDVILKO, 1916, which are monoecious on monocotyledones, but probably had host-alternating ancestors with Cornus as the primary host. If for example Anoecia corni (FABRICIUS, 1775) became monoecious on Cornus, then we would have the same situation as that between a relative of Stomaphis on a tree and species of Tramini on roots of herbs. Anoecia corni feeds however on leaves, which are poor in amino acids in summer, so that it is advantageous to migrate to the secondary hosts, while for Stomaphis it is not so, because it feeds on tree trunks, where some amino acids are still available in summer, and furthermore it is strongly protected by ants during the whole summer.

An extinct species, probably the ancestor of both Lachnidae and Aphididae, became long ago host-alternating and acquired herbs as secondary hosts. These herbs were probably composites (Asteraceae). Composites became numerous in the middle of the Tertiary 
(GRAHAM 1996) or later (GOTHAN \& WEYLAND (1964), when the world flora changed as a result of climatic changes (HEIE 1994). Steppes and savannas with a lot of grasses and other herbs became dominant in the Miocene (Boule \& PIVETEAU 1935) in large parts of the continents of the northern hemisphere making it possible for many of the aphidids to conquer these herbaceous plants as hosts and also for the lachnids. Tramini are mostly anholocylic and produce rather few alatae, which must mean that they have lost their ability to return to a primary host, and as they are protected by ants they do not need to migrate, especially because roots need amino acids. If the Tramini lost their primary hosts, then other lachnids must have lost their secondary host. It is of course true that the hostalternating lachnids are not among the still living species.

The kind of host alternation evolved by ancestral Lachnidae is a big question. It might have been the same kind as in Eriosomatidae, Anoeciidae and Hormaphididae, where the autumn migration takes place by alate sexuparae producing rather small apterous sexuales on the primary host. Alternatively it might have been the same kind as in Aphididae, where the autumn migration takes place by alate gynoparae producing apterous oviparae on the primary host and alate males, both of about the same size as the viviparous females. Among the ancestors with host alternation existing in the past some must be related to Stomaphis. The sexuales of this genus are rather small, and the male has no rostrum just as the sexuales of the Eriosomatidae. But Stomaphis is the only lachnid genus with dwarfish sexuales, which supports the idea, that the ancestors had host alternation of the same kind as in Aphididae, and the presence of alate males in many lachnid species also supports this idea. BLACKMAN et al. (2001) studied the rare sexuales in Trama and found that the oviparous female was of the same size as the viviparous females, while the male was apterous and somewhat smaller.

It is also a question when host alternation evolved. In my opinion it happened in the ancestor of both families. In any case it must have happened long enough ago to make Tramini look morphologically very different from all other lachnids being paler and having very long hind tarsi and reduced eyes.

The idea that host alternation has developed more than once within Aphididae has been presented by VON DOHLEN et al. (2006), but I have later changed my mind (HEIE \& WeGIEREK 2009). This idea was based on DNA-studies indicating that Pterocomma BuCKTON, 1879 and Cavariella DEL GERCIO, 1911 are closely interrelated, though they look very different from each other. ORTIZ-RIVAS \& MARTINEZ-TORRES (2010), and also NORMARK (2000), found to the contrary that Pterocommatinae separated from the base of the aphidid branch, also using DNA-analysis. I now believe that the development of genes causing host alternation happened only once, because the kind of host alternation, that is found in Cavariella spp. is exactly the same as that found in Aphis, Rhopalosiphum, Macrosiphum and many other aphidids. Also Pterocomma and its relatives must have had 
host alternating ancestors and only lost host alternation because they were protected by ants on their original primary hosts (members of Salicaceae) and did not feed on leaves, which in summer become nutritionally poor. This must be true whether the pterocommatines branched at the base of the aphidid branch or higher. In fact all aphidids and lachnids feeding on roots or branches or trunks of trees are monoecious, e.g. Pterocomma spp. and Aphis spp. and most lachnids. The ancestor of Tramini may consequently have lived on leaves or young shoots of the tree, which was its primary host plant.

The development of genes giving rise to a dioecious life cycle must be very old, old enough to be found in the ancestor of both Aphididae and Lachnidae. A definitive answer to this question cannot be given, but I believe that it happed in one step. All species of Lachnidae and some species of Aphididae later became monoecious, and some of the latter have given rise to dioecious species as a result of dormant genes (JouSSELIN et al. 2010).

The theory that the ancestor of Lachnidae was host-alternating is not new. It was presented by MORDVILKO $(1934,1935)$ and later by $\operatorname{HeIE}(1980,1995)$.

It may be true that some lachnid characters are real plesiomorphies just like the presence of siphuncular pores, e.g. the very short processus terminalis, the longitudinal frontal suture and the presence of all wing veins in most species, perhaps also the large body size, while other characters are real apomorphies, e.g. the emergence of the radial sector from the middle or apical part of the pterostigma, the reduction of accessory glands in the male reproductive system (WOJCIECHOWSKI 1992), and the circular or oval shape of the secondary rhinaria, a character shared with the Aphididae and Greenideidae and also some drepanosiphids.

The family Lachnidae consisted of rather few species or perhaps none in the beginning of the Tertiary. In the Middle Miocene, when large parts of the continents on the northern hemisphere began to be covered by huge coniferous forests, it grew in number of species, especially later just before the glacial periods (HEIE 1995). All the 223 Cinara species are very similar and difficult to identify, so obviously they evolved at about the same time not very long ago in an explosive adaptive radiation.

An apomorphy of all lachnids on trees caused by adaptation is the long rostrum, nearly as long as the body in some Cinara spp. and much longer than the body in Stomaphis. This character makes it possible to reach the bottom of fissures in the bark of trunks or thick branches of the trees used as hosts. It is a character developed many times. It is also found in many extinct aphids, e. g. Germaraphis HeIE, 1967, all species of Mesozoicaphididae and some species of Tajmyraphididae, which are not related to the Lachnidae, but probably likewise associated with tree trunks or thick branches. 
Perhaps the basal position of Lachnidae in the phylogenetic tree found by ORTIZ-RIVAS \& MARTINEZ-TORRES (2010) is caused by many mutations of genes responsible for many apomorphies?

\section{ACKNOWLEDGEMENTS}

I want to to thank Carol VON DOHLEN and Roger BACKMAN for advice and for sending me some relevant papers, but the author is the only responsible person.

\section{REFERENCES}

BAKER A.C. 1920. Generic classification of the hemipterous family Aphididae. Bulletin of the United States Department of Agriculture, 826: 1-109.

Blackman R.L., DE Boise E., Czylok A. 2001. Occurrence of sexual morphs of Trama troglodytes VON HEYDEN, 1837. Journal of Natural History 35(5): 779-785.

BLACKMAN R.L., EASTOP V.F. 1994. Aphids on the world's trees, An identification and information guide. CAB International and Natural History Museum, Wallingford - London.

BÖRNER C. 1952. Europae centralis Aphides. Mitteilungen der Türingischen Botanischen Gesellschaft, Beiheft 3: 1-488.

Boule M., Piveteau J. 1935. Élements de Paléontologie. P. Masson, Paris.

CZYLOK A. 1990. Phylogenetic concept of Tramini (Homoptera, Lachnidae). Uniwersytet Śląski, Katowice.

Dohlen C.D. von, Rowe C.A., HeIE O.E. 2006. A test of morphological hypotheses for tribal and subtribal relationships of Aphidinae (Insecta; Hemiptera: Aphididae) using DNA sequences. Molecular Phylogenetics and Evolution 38(2): 316-329.

Gothan W., WeYland H. 1964. Lehrbuch der Paläobotanik. Akademie-Verlag, Berlin.

GRAhAm A. 1996. A contribution to the geologic history of the Compositae. [in:] D.J.N. HiND, H. BeEntJe (eds.). Compositae: Systematics. Proceedings of the International Compositae Conference, Kew, 1994. Royal Botanical Gardens, Kew, 123-140.

HEIE O.E. 1964. Aphids collected in Iceland in August 1961. Entomologiske Meddelelser 32: 220-235.

HEIE O.E. 1967. Studies of fossil aphids (Homoptera: Aphidoidea). Spolia Zoologica Musei Haunensis 26: 1-273.

HEIE O.E. 1980. Fauna Entomologica Scandinavica vol. 9. The Aphidoidea of Fennoscandia and Denmark I. General part. The families Mindaridae, Hormaphididae, Thelaxidae, Anoeciidae, and Pemphigidae. Scandinavian Science Press Ltd., Klampenborg.

HEIE O.E. 1994. Why are there so few aphid species in the temperate areas of the southern hemisphere. European Journal of Entomology 91(1): 127-133. 
HeIE O.E. 1995. Fauna Entomologica Scandinavica vol. 31. The Aphidoidea of Fennoscandia and Denmark. VI. Part 3 of Macrosiphini and family Lachnidae. Brill, Leiden.

HeIE O.E. 2005. Fossil aphids (Hemiptera: Sternorrhyncha) from Canadian Cretaceous amber and from the Miocene of Nevada. Insect Systatics and Evolution 37(1): 91-104.

HeIE O.E., FrIEDRICH W.L. 1971. A fossil specimen of the North American Hickory Aphid (Longistigma caryae HARRIS), found in Tertiary deposits in Iceland. Entomologica Scandinavica 2: 74-80.

Heie O.E., Wegierek P. 1998. A list of fossil aphids. Annals of the Upper Silesian Museum in Bytom (Entomology) 8-9: 159-192.

Heie O.E., WegiereK P. 2009. A classification of the Aphidomorpha (Hemiptera: Stenorrhyncha) under consideration of the fossil taxa. Redia 92: 69-77.

Heie O.E., WegiereK P. 2011. Monographs of the Upper Silesian Museum No. 8. A list of fossil aphids (Hemiptera, Sternorrhyncha, Aphidomorpha). Upper Silesian Museum, Bytom.

Hille Ris Lambers D. 1964. Higher categories of the Aphididae. [in:] E.S. SYlvester (ed.). Abstracts of the Papers Presented at the Seminar on the Current Status of Research of Aphids. Berkeley, California, U.S.A.

Huang D., Wegierek P., ŻyŁa D., Nel A. 2012. The oldest aphid of the family Oviparosiphidae (Hemiptera: Aphidoidea) from the Middle Jurassic of China. European Journal of Entomology 112(1): 187-192.

Jousselin J., Genson G., Coeur D’ACIER A. 2010. Evolutionary lability of a complex life cycle in the aphid genus Brachycaudus. BMC Evolutionary Biology 10: 295.

Koch L.L. 1854-1857. Die Pflanzenläuse Aphiden, getreu nach dem Leben abgebildet und beschrieben. Verlag von J. L. Lotzbeck, Nürnberg.

KonONOva E.L. 1977. New aphid species (Homoptera, Aphidinea) from Upper Cretaceous deposits of the Tajmyr. Entomogicheskoe obozrenie 56(3): 588-600. (in Russian)

LAMPEL G., BURGENER R. 1985. Taxonomisch-morphologische Untersuchungen an Baumläusen (Homoptera, Aphidina, Lachnidae). Bulletin de la Société Fribourgeoise des Sciences Naturelles 75(1-2): 188-215.

LAMPEL G., BURGENER R. 1987. The genetic relationships between lachnid taxa as established by enzyme-gel-electrophoresis. [in:] J. Holman (ed.). Population structure, genetics and taxonomy of Aphids and Thysanoptera. Proceedings of international symposia, held at Smolenice, Czechoslovakia, September 9-14, 1985. SPB Academic Publishing, The Hague, The Netherlands, 71-95.

MACKAUER M. 1965. Parasitological data as an aid in aphid classification. The Canadian Entomologist 97(10): 1016-1024.

MoRdVILKo A. 1934. On the evolution of aphids. Archiv für Naturgeschichte N.F. 3: 1-60.

MoRdvilko A. 1935. Die Blattläuse mit unvollständigem Genarationszyklus und ihre Entstehung. Ergebnisse und Fortschritte aus der Zoologie 8: 36-328.

NORMARK B.B. 2000. Molecular systematics and evolution of the aphid family Lachnidae. Molecular Phylogenetics and Evolution 14(1): 131-140. 
Nováková E., Hypša V., Klein J., Foottit R.G., von Dohlen C.D., Moran N.A. 2013. Reconstructing the phylogeny of aphids (Hemiptera: Aphididae) using DNA of the obligate symbiont Buchnera aphidicola. Molecular Phylogenetics and Evolution 68(1): 42-54.

OrtiZ-Rivas B., MartineZ-Torres D. 2010. Combination of molecular data support the existence of three main lineages in the phylogeny of aphids (Hemiptera: Aphididae) and the basal position of the subfamily Lachninae. Molecular Phylogenetics and Evolution 55(1): 305-317.

PoINAR G. JR., BRown A.E. 2005. New Aphidoidea (Hemiptera; Sternorrhyncha) in Burmese amber. Proceedings of the Entomological Society of Washington 107(4): 835-845.

Remaudière G., Remaudière M. 1997. Catalogue des Aphididae du monde. INRA Editions, Versailles.

WojCIECHOWSKI W. 1992. Studies on the systematic system of aphids (Homoptera, Aphidoidea). Uniwersytet Śląski, Katowice.

Zhang G., Chen X. 1999. Studies on the phylogeny and host plant association of Lachnidae (Homptera: Aphidinea). Entomologica Sinica 6(3): 193-208.

Zhang J.F., Sun B., Zhang X. 1994. Miocene insects and spiders from Shanwang, Shandong. Science Press, Beijing. (in Chinese)

Received: 27 August 2015

Accepted: 21 October 2015 